\title{
The Host Range of the Stem-Boring Weevil, Listronotus setosipennis (Coleoptera: Curculionidae) Proposed for the Biological Control of Parthenium hysterophorus (Asteraceae) in Pakistan
}

\author{
Philip Sebastian Richard Weyl ${ }^{1, *(\mathbb{D}}$, Abdul Rehman ${ }^{2}$ and Kazam Ali ${ }^{2}$ \\ 1 Centre for Agriculture and Biosciences International (CABI), Rue des Grillons 1, 2800 Delémont, Switzerland \\ 2 Centre for Agriculture and Biosciences International (CABI), Opposite 1-A, Data Gunj Baksh Road Satellite \\ Town, Rawalpindi 43600, Pakistan; a.rehman@cabi.org (A.R.); k.ali@cabi.org (K.A.) \\ * Correspondence: p.weyl@cabi.org
}

check for updates

Citation: Weyl, P.S.R.; Rehman, A.; Ali, K. The Host Range of the Stem-Boring Weevil, Listronotus setosipennis (Coleoptera:

Curculionidae) Proposed for the Biological Control of Parthenium hysterophorus (Asteraceae) in Pakistan. Insects 2021, 12, 463. https:// doi.org/10.3390/insects12050463

Academic Editors: Brian G. Rector and Massimo Cristofaro

Received: 14 April 2021

Accepted: 13 May 2021

Published: 17 May 2021

Publisher's Note: MDPI stays neutral with regard to jurisdictional claims in published maps and institutional affiliations.

Copyright: (c) 2021 by the authors. Licensee MDPI, Basel, Switzerland. This article is an open access article distributed under the terms and conditions of the Creative Commons Attribution (CC BY) license (https:/ / creativecommons.org/licenses/by/ $4.0 /)$.
Simple Summary: Parthenium is an extremely damaging weed in Pakistan and there are not many sustainable and effective management options for its control. Biological control may offer a solution, provided that effective and safe agents are released. In this study we explore the host range of a weevil, Listronotus setosipennis, in a Pakistani context. We tested several native and crop or ornamental species that have cultural importance in Pakistan. Our results suggest that the risk of releasing this weevil into Pakistan for the control of parthenium is extremely low and the benefits are likely to be great.

Abstract: Parthenium, or Parthenium hysterophorus, has extended its range in Pakistan throughout Punjab and into Khyber Pakhtunkhwa, the Federally Administrated Tribal Areas, Azad Jammu and Kashmir, and Sindh Provinces. Without control measures against parthenium, the negative impacts of this weed will go unchecked having deleterious effects on native biodiversity, human and animal health, as well as crop productivity. The weevil Listronotus setosipennis was obtained and imported from the Plant Health and Protection of the Agricultural Research Council (ARC-PHP), at Cedara, South Africa, in April 2019. A total of 22 plant species or cultivars in the Asteraceae family were assessed during no-choice oviposition tests in Pakistan and South Africa. During these tests, the only plant species accepted for oviposition were the 10 cultivars of Helianthus annuus that are grown in Pakistan. All cultivars were thus tested for development of L. setosipennis from egg to adult. Only three cultivars were able to support some larval development, but at such low levels that it is unlikely to be the basis of a viable population. The results concur with native (Argentina) and introduced (Australia) field host-range information where L. setosipennis has never been recorded as a pest of sunflowers. The results of laboratory-based host-range trials, together with host records from its native and introduced range, indicate that L. setosipennis is sufficiently specific to parthenium and is thus suitable for release in Pakistan.

Keywords: classical biological control; invasive weed; exotic; weevil; stem miner; sunflower

\section{Introduction}

Parthenium hysterophorus L. ("parthenium") is a highly invasive ruderal annual weed which is spreading rapidly through vast areas of the tropics and sub-tropics, with highly deleterious effects on native biodiversity, human and animal health, and productivity of both crops and grasslands [1]. Parthenium has an extensive native range in the Americas, occurring in the eastern USA as far north as New York and Ohio, throughout Mexico and Central America into South America, and extending as far as Argentina and Chile [2,3]. It was first recorded outside its native range in the 19th century (1810 in India, 1880 in South Africa), but most introductions date from the 1950s and 1960s. Parthenium has since then 
invaded 48 countries, as reported by Shabbir et al. [1]. In Pakistan, parthenium was first reported from Gujarat district of the Punjab Province in the 1980s [4]. For the first 20 years following its introduction it remained restricted to northern Punjab, but since 2000, its range has extended throughout Punjab and into Khyber Pakhtunkhwa (KP), the Federally Administrated Tribal Areas (FATA), Azad Jammu and Kashmir, and Sindh Provinces. It has spread along roads, canals and rivers, and the invasion has been further exacerbated by irrigation and floods [5]. Parthenium is rapidly spreading in various parts of Punjab, $\mathrm{KP}$ and Kashmir, and is becoming a dominant weed in different terrestrial ecosystems. The weed is highly invasive and is reported as a major weed for agro-ecosystems in Pakistan [6-14].

It is widely acknowledged that integrated control is the most effective strategy in managing pests. In the case of plants, it involves the use of herbicides, manual or mechanical control, and biological control agents in an integrated way. The main benefits of classical biological control are that the agents establish self-perpetuating populations and often establish throughout the range of the target weed, including areas which are not accessible for chemical or physical control; control of the weed is permanent; the cost is low relative to other approaches and usually requires a once-off investment; and benefits can be reaped by many stakeholders regardless of their financial status and whether they contributed to the initial research [15]. Pakistan does not have a long history of weed biological control, with only a single introduction of a single agent, Cactoblastis cactorum against Opuntia species [16].

In most cases, weed biological control relies on a classical biological control approach, in which natural enemies from the native range have been intentionally released as biological control agents in the introduced range after host range testing. In some cases, however, the agent has been found to be already present following an unknown or accidental introduction. In Pakistan, biological control options against parthenium are limited and there have so far been no deliberate introductions of agents to control parthenium. Nevertheless, Zygogramma bicolorata Pallister, known as the Mexican or parthenium leaf beetle, which was deliberately introduced from Mexico to India in 1983, was reported in Pakistan in 2006 and now has a widespread distribution in the country [17]. The inadvertent introduction of Z. bicolorata has offered Pakistan an opportunity to benefit from the biological control of parthenium with limited investment into host range testing and applications for permissions for release. Although future research into the biology, ecology and impact of this species in Pakistan is warranted, studies have shown that this species alone is unlikely to achieve full control of parthenium [18].

The winter rust, Puccinia abrupta Diet. \& Holw. var. partheniicola (Jackson) Parmelee, has also been recorded from Pakistan and is now widely distributed throughout the range of parthenium in Pakistan [19,20]. Although the presence of this rust in Pakistan will aid in the management of parthenium, it is likely that its impact will be limited by abiotic factors. Temperature and dewpoint have been shown to be the limiting factors for urediniospore infection and survival, thus limiting impact of this rust in Australia where it was deliberately introduced [18]. Whilst it would be useful to monitor the distribution of this rust on an annual basis in winter, any redistribution would be unlikely to achieve a better level of control than is already experienced in the field [20].

Therefore, strategically, the resources available for biological control should focus on the evaluation of additional agents for release into Pakistan in order to obtain long-term sustainable control of parthenium [20]. The stem-boring weevil, Listronotus setosipennis (Hustache), another potential biological control agent for parthenium, is native to Brazil and Argentina. This weevil has had previous testing in Australia [21], South Africa and Ethiopia [22], which indicated that it is host specific and a safe biological control agent and has been released in these three countries as well as Uganda [23]. With a view of evaluating L. setosipennis as a biological control agent for parthenium in Pakistan, CABI applied for the importation of this weevil to perform host range testing in its post entry quarantine facility in Rawalpindi [20]. The national quarantine authorities (Plant Sciences Division of 
the Pakistan Agricultural Research Council (PSD PARC)) approved the importation of the weevil specifically for this purpose, and adult $L$. setosipennis were imported from the rearing facility of the Plant Health and Protection of the Agricultural Research Council (ARC-PHP), at Cedara, South Africa, in April 2019 [20]. The import permit for L. setosipennis was issued by the Ministry of National Food Security and Research, Department of Plant Protection, Plant Quarantine Division under permit number IPKA-3787-016/18-2019. The aim of this study was to determine the host specificity of L. setosipennis in a Pakistani context.

\section{Materials and Methods}

\subsection{Host-Range Testing}

2.1.1. Test Plant List Appropriate for Pakistan

It is generally accepted that species closely related to the target species are at greater risk of attack than species more distantly related. Therefore, test plant lists are established based on phylogenetic relationships between the target weed and other plant species [24]. The family Asteraceae is one of the most diverse and widespread families of vascular dicotyledonous plants, with species that are perennial, annual or biennial herbs, sub-shrubs and shrubs. The members of this family are abundantly present throughout the world except the Antarctica region [25]. The Asteraceae is a large family in Pakistan, which is represented by 758 species in 15 tribes. The tribe Heliantheae to which Parthenium hysterophorus belongs is only represented by 27 species in Pakistan. Comprehensive testing of the host range of L. setosipennis has already been done in several countries including Australia [21], Ethiopia, and South Africa [22] (Table S1). In addition to this, a total of 19 species and/or cultivars within Heliantheae have already been tested in Australia and Ethiopia. Since so many species have already been tested in a wide range of families and tribes, as well as specifically in Heliantheae, a condensed test plant list is justified for Pakistan (22 species and/or cultivars), focusing on native and crop or ornamental species that have overlapping distributions with parthenium and are likely to be at a higher risk of non-target attack (Table 1). During the process of the formation of the test plant list, advice and input was received from Dr. Amir Sultan, PSO, National Herbarium, NARC, Pakistan. The final test list contained representatives of eight tribes with both native and crop species (as well as ornamentals) of economic and cultural importance in Pakistan (Table 1). In this case, Pakistan has been able to greatly benefit from the guidance of the ARC-PHP, South Africa, as well as work already done in other countries, namely Australia and Ethiopia, which has significantly reduced the cost and time required for the evaluation of the biological control agent L. setosipennis.

\subsubsection{Insect Cultures}

Following importation from the ARC-PHP, Cedara, South Africa, the L. setosipennis culture was built up and maintained in the Pakistan quarantine at a day/night cycle of 14 $\mathrm{L}: 10 \mathrm{D}$, mean temperature of $25 \pm 5^{\circ} \mathrm{C}$, and mean relative humidity of $65 \pm 5 \%$. Due to space limitations, it was only possible to maintain a culture of approximately 1000 adult weevils. For detailed biology of this weevil, refer to [21]. 
Table 1. The no-choice oviposition tests with Listronotus setosipennis against indigenous and economically important Asteraceae plant species in Pakistan between 2019 and 2020.

\begin{tabular}{|c|c|c|c|}
\hline $\begin{array}{l}\text { FAMILY } \\
\text { Tribe } \\
\text { Species }\end{array}$ & Common Name & $\begin{array}{l}\text { No. Valid } \\
\text { Replicates }\end{array}$ & $\begin{array}{l}\text { No. of Eggs } \\
\text { Mean } \pm \text { SE }\end{array}$ \\
\hline \multicolumn{4}{|l|}{ ASTERACEAE } \\
\hline \multicolumn{4}{|l|}{ Heliantheae } \\
\hline Parthenium hysterophorus & Gajar booti & 25 & $185.5 \pm 15.2$ \\
\hline Cosmos bipinnatus $\mathrm{E}$ & Cosmos & 4 & $0 \pm 0$ \\
\hline Eclipta prostrata I & Bhangra weed & 4 & $0 \pm 0$ \\
\hline Helianthus annuus $(\mathrm{S} 278) * \mathrm{E}$ & Sunflower & 5 & $5.4 \pm 1.7$ \\
\hline Helianthus annuus (ParSun-3) * E & Sunflower & 5 & $16.2 \pm 5.3$ \\
\hline Helianthus annuus (SF-0054) * E & Sunflower & 5 & $9.6 \pm 2.7$ \\
\hline Helianthus annuus (KQS-FSH-1) * E & Sunflower & 5 & $9.8 \pm 5.0$ \\
\hline Helianthus annuus (S-3950) * E & Sunflower & 5 & $18.0 \pm 7.9$ \\
\hline Helianthus annuus (FMC-2) * E & Sunflower & 5 & $5.4 \pm 2.0$ \\
\hline Helianthus annuus $(\mathrm{S}-2216) * \mathrm{E}$ & Sunflower & 5 & $12.8 \pm 5.7$ \\
\hline Helianthus annuus (ESNH-013) * E & Sunflower & 5 & $20.6 \pm 6.3$ \\
\hline Helianthus annuus (HySun-33) * E & Sunflower & 5 & $5.6 \pm 4.5$ \\
\hline Helianthus annuus (SX-4045) *E & Sunflower & 5 & $5.6 \pm 3.7$ \\
\hline Rudbeckia laciniata $\mathrm{E}$ & Black-eyed Susan & 4 & $0 \pm 0$ \\
\hline Zinnia elegans $\mathrm{E}$ & Zinnia & 4 & $0 \pm 0$ \\
\hline \multicolumn{4}{|l|}{ Anthemideae } \\
\hline Dendranthema indica $\mathrm{E}$ & Gul-e-Daudi & 4 & $0 \pm 0$ \\
\hline \multicolumn{4}{|l|}{ Astereae } \\
\hline Callistephus chinensis $\mathrm{E}$ & Aster & 4 & $0 \pm 0$ \\
\hline \multicolumn{4}{|l|}{ Calenduleae } \\
\hline Calendula officinalis $\mathrm{E}$ & Pot marigold & 4 & $0 \pm 0$ \\
\hline \multicolumn{4}{|l|}{ Cicorieae } \\
\hline Lactuca sativa $^{\mathrm{E}}$ & Lettuce & 4 & $0 \pm 0$ \\
\hline \multicolumn{4}{|l|}{ Coreopsideae } \\
\hline Dahlia pinnata $\mathrm{E}$ & Dahlia & 4 & $0 \pm 0$ \\
\hline Bidens bipinnata $\mathrm{I}$ & Bidens & 4 & $0 \pm 0$ \\
\hline \multicolumn{4}{|l|}{ Cynareae } \\
\hline Carthamus tinctorius $\mathrm{E}$ & Safflower & 4 & $0 \pm 0$ \\
\hline \multicolumn{4}{|l|}{ Tageteae } \\
\hline Tagetes erecta $\mathrm{E}$ & Gul-e-Ashrafii & 4 & $0 \pm 0$ \\
\hline
\end{tabular}

\subsubsection{General Considerations for Host Range Trials}

In all tests, potted plants (not excised leaves or stems) were used to ensure that test conditions were as optimal as possible. Depending on the size of the plant, the appropriate pot size was used, ranging from 1-4 L pots, filled with a standard commercial potting soil. Standardized potting soil was prepared by mixing $18 \mathrm{~kg}$ of all-purpose potting soil (Miracle-Gro) with $185 \mathrm{~g}$ Osmocote fertilizer with N:P:K of 19-6-12 and $125 \mathrm{~g}$ Dolomite lime. The plants were watered ad libitum. Each test plant was ensured to be in the correct phenological stage for oviposition, which was flowering with still-developing florets.

We followed a typical host range testing procedure, following recommendations by [24], to assess the physiological and ecological host range. The physiological host range encompasses all plant species on which the insect, in this case L. setosipennis, can develop under no-choice conditions [26], while the ecological host range includes plant species which are utilized under natural conditions [26]. The testing sequence progressively reduces the degree of restriction, deleting unattacked plants at each stage, until only a few remain to be tested under conditions as natural as possible. This has proven to be a reliable way to determine the safety of potential biological control agents. Unfortunately, under quarantine conditions at the CABI post entry quarantine facility in Rawalpindi, multiple- 
choice tests were not possible due to space limitations, and thus the data presented in this study are conservative and likely exaggerate the potential risk.

\subsubsection{No-Choice Oviposition Tests}

Following guidance by ARC-PHP, South Africa, and previous studies [22], five pairs of adults were exposed to a single test or parthenium control plant at the correct phenological stage, in this case flowering, in individual fine mesh cages with mesh diameter of $1 \mathrm{~mm}^{2}$ (SE-1836) of dimensions $45 \times 45 \times 90 \mathrm{~cm}$ for five days, with a day/night cycle of $14 \mathrm{~L}: 10 \mathrm{D}$, mean temperature of $25 \pm 5{ }^{\circ} \mathrm{C}$, and mean relative humidity of $65 \pm 5 \%$. Typical in host range testing, for each experimental setup, there was also a control plant. The no-choice tests were run in four consecutive series of experiments between 2019 and 2020.

\subsubsection{Larval Development Tests}

During the no-choice tests, oviposition was recorded only on the 10 sunflower cultivars and not on any of the other plant species tested. However, since sunflower is an important crop in Pakistan and oviposition has also been recorded on this species in Australia [21] and South Africa [27], it was considered a critical species. Due to space constraints in quarantine, in Pakistan, efforts were focused on larval development tests to determine whether this weevil would be able to sustain a viable population and thus cause damage to sunflower. Ten cultivars commonly grown in Pakistan (Table 2) were propagated in pots, and a total of four replicates for each were conducted, as well as for eight control plants.

A total of 30 eggs were placed on each sunflower plant, as well as the control plant, and each plant was kept in individual fine mesh cages (SE-1872) of dimensions $45 \times 45 \times 180 \mathrm{~cm}$ for 11 weeks. Each cage was inspected regularly for the emergence of adults, and after about 11 weeks, all plants were dissected, and the number of larvae and pupae were recorded. To test whether there is a difference between the number of adults emerging from parthenium compared to the sunflower cultivars, the non-parametric independent samples Kruskal-Wallis test was conducted. In addition to this, the same test was run excluding the control plant to determine whether there is a difference between the likelihood of any sunflower cultivars supporting the development of L. setosipennis. Data were analysed using IBM SPSS Statistics v25 (SPSS Inc., Chicago, IL, USA).

\section{Results}

\subsection{No-Choice Oviposition Tests}

In the no-choice tests, adult feeding was sporadic and difficult to quantify (or even find in some cases) and thus was deemed negligible and not recorded. In the no-choice oviposition tests, all 10 sunflower (H. annuus) cultivars that were assessed received eggs by $L$. setosipennis females, while all other test plants were completely avoided and no eggs were recorded (Table 1$)$. Average $( \pm \mathrm{SE})$ egg numbers on sunflowers ranged from $5.40 \pm 1.9$ (cultivar FMC-2) and $5.40 \pm 1.7$ cultivar S278 to $20.6 \pm 6.3$ on cultivar ESNH-013, compared to $185.5 \pm 15.2$ on parthenium as the control. The difference in numbers of eggs oviposited on the sunflower test cultivars compared to the control plants was highly significant (Kruskal-Wallis, $\mathrm{H}=52.8 ; \mathrm{df}=12 ; p<0.001$ ).

\subsection{Larval Development Tests}

The ten sunflower cultivars that are considered important in Pakistan were tested in larval development tests. Development was only recorded on three sunflower cultivars (four individual plants) (ParSun-3, S-278, Hysun-33), and only six adults emerged from a total of 1200 eggs exposed to sunflower plants (single adult on ParSun-3, while two adults on one replicate of cultivar Hysun-33, and finally two replicates of S-278 supported development of one and two adults each). When only considering the three cultivars where development occurred, survival from egg to adult is $2.5 \%$ or less, and if all cultivars are considered, the likelihood of survival is $0.5 \%$. In contrast, on their usual host, parthenium, there was a much greater survival from egg to adult of over $40 \%$. There were significantly 
fewer adults on the sunflower cultivars in comparison to the successful development recorded on the parthenium plants setup, with a total of 103 adults from 240 eggs (KruskalWallis, $\mathrm{H}=37.777 ; \mathrm{df}=10 ; p<0.0001$ ) (Table 2). When the data from the control plants were excluded from the analyses, there was no difference in the likelihood of any sunflower cultivar supporting development to adult, suggesting that no one cultivar is more at risk, but rather that all cultivars are at low risk (Kruskal-Wallis, $\mathrm{H}=11.897 ; \mathrm{df}=9 ; p<0.219$ ). The very low ability to complete development to the adult stage strongly indicates an inability to sustain a viable population on these sunflower cultivars.

Table 2. Development of Listronotus setosipennis larvae arising from 30 eggs per replicate on sunflower cultivars that are considered important in Pakistan.

\begin{tabular}{ccccc}
\hline Plant Species & $\begin{array}{c}\text { No. Valid } \\
\text { Replicates }\end{array}$ & $\begin{array}{c}\text { No. of Adults } \\
\text { Emerged Mean } \pm \text { SE }\end{array}$ & $\begin{array}{c}\text { No. of Pupae } \\
\text { Mean } \pm \text { SE }\end{array}$ & $\begin{array}{c}\text { No. of Live Larvae } \\
\text { Mean } \pm \text { SE }\end{array}$ \\
\hline Parthenium hysterophorus & 8 & $12.88 \pm 1.56$ & $0.50 \pm 0.27$ & $3.63 \pm 0.75$ \\
Helianthus annuus (S278) & 4 & $0.75 \pm 0.48$ & 0 & 0 \\
Helianthus annuus (ParSun-3) & 4 & $0.25 \pm 0.25$ & 0 & 0 \\
Helianthus annuus (SF-0054) & 4 & 0 & 0 & 0 \\
Helianthus annuus (KQS-FSH-1) & 4 & 0 & 0 & 0 \\
Helianthus annuus (S-3950) & 4 & 0 & 0 & 0 \\
Helianthus annuus (FMC-2) & 4 & 0 & 0 & 0 \\
Helianthus annuus (S-2216) & 4 & 0 & 0 & 0 \\
Helianthus annuus (ESNH-013) & 4 & 0 & 0 & 0 \\
Helianthus annuus (HySun-33) & 4 & $0.50 \pm 0.50$ & 0 & 0 \\
Helianthus annuus (SX-4045) & 4 & 0 & 0 \\
\hline
\end{tabular}

\section{Discussion}

The results from the current study on the host range of L. setosipennis in a Pakistani context suggest that it is a safe biological control agent for release. Of the 22 Asteraceae plant species that were tested under no-choice conditions, oviposition by L. setosipennis was recorded only on the sunflower cultivars tested, suggesting a narrow physiological host range. These results are in line with other host range tests already conducted in Australia [21] and Ethiopia [22], where 68 plant species from 26 families and 31 plant species from 7 families were investigated, respectively. Limited oviposition was recorded on Zinnia and Helianthus annuus cultivars in no-choice tests conducted in Brazil and Australia [21], while Ethiopian tests had no non-target oviposition [22]. In quarantine multiple-choice cage tests with adults in Australia, there was no feeding or oviposition on any of the test plants, but between 19 and 90 eggs were laid on the parthenium plants in each test [21]. This is not unusual under cage conditions in quarantine, and further assessment of larval development indicated extremely low risk of L. setosipennis being able to sustain a population on sunflowers. Guided by these results, L. setosipennis was shown to be safe for release in three countries and first released in 1982 in Australia, 2013 in South Africa, 2016 in Ethiopia, and 2018 in Uganda [23].

Given that sunflower is an important crop worldwide, typically, for testing in Pakistan, sunflower should have been tested under multiple-choice conditions to obtain an understanding of the realized host range; however, due to space limitations in the quarantine facility in Pakistan, this was not possible, so efforts were focused on only conducting larval development tests. Thus, the data presented in this study are conservative and likely overinflate the risk. Despite this, there was only minor survival and development recorded on three cultivars, namely ParSun-3, S-278, and Hysun-33; however, when comparing between cultivars, the number of adults does not suggest that one is more at risk than another, but rather that all varieties are at low risk. Given that the probability of development is between 0.5 and $2.5 \%$, this suggests that sunflower is unlikely to sustain a viable population, and L. setosipennis will not cause any major damage to any sunflower cultivars tested in the current study. In addition to this, L. setosipennis has never been recorded as a pest or even known by entomologists in South America [21]. 
There is no doubt that parthenium is a major problem in Pakistan [6-14], and control of this weed is imperative. Chemical control, although effective in Pakistan [28], is not a long-term solution, as it is extremely expensive and known to require several successive applications [29]. Biological control is known to offer a sustainable and effective option in several cases, especially in low and middle income countries [30], and L. setosipennis is no exception for Pakistan. In Pakistan, two biological control agents against parthenium are present, Z. bicolorata and P. abrupta var. partheniicola [20]; however, their impact is not considered sufficient, and additional agents are required. In Australia, where biological control is considered successful, nine different agents were required to be released [31]. Building on this success, additional agents should be studied for release in Pakistan in the future.

\section{Conclusions}

The only known host of L. setosipennis in its native range of Argentina is parthenium [21]. The Australian research programme assessed 68 non-target plant species, including 18 members of the Asteraceae (including six sunflower cultivars) as well as commercially cultivated members from another 25 families [21]. In South Africa, L. setosipennis was tested on 38 native and economically important non-target Asteraceae species and 13 H. annuus cultivars [27], while in Ethiopia, it was evaluated on 31 plant species [22]. All countries where it has been released concluded that L. setosipennis is host specific and a safe biological control agent for use against parthenium, leading to approval for release by all regulatory authorities after a thorough review of submitted risk assessments. The quarantine laboratory assessments of the host range of L. setosipennis conducted in Pakistan are in line with these findings and in combination with evidence of the weevil's native field host range in South America and introduced field host range in Australia and Ethiopia indicate that it is highly unlikely that L. setosipennis will cause any damage to any plant, native or cultivated, other than parthenium, in Pakistan.

Supplementary Materials: The following are available online at https:/ /www.mdpi.com/article/ 10.3390/insects12050463/s1, Table S1: The test plant species from Australia and Ethiopia that have already been tested with Listronotus setosipennis in each respective country prior to release. Each country found no evidence for the potential of L. setosipennis to have non-target impacts on either native or economically important crop species.

Author Contributions: Conceptualization, P.S.R.W., A.R. and K.A.; methodology, P.S.R.W., A.R. and K.A.; software, P.S.R.W., A.R. and K.A.; validation, P.S.R.W., A.R. and K.A.; formal analysis, P.S.R.W., A.R. and K.A.; investigation, P.S.R.W., A.R. and K.A.; resources, P.S.R.W., A.R. and K.A.; data curation, P.S.R.W., A.R. and K.A.; writing —original draft preparation, P.S.R.W.; writing—review and editing, A.R. and K.A. All authors have read and agreed to the published version of the manuscript.

Funding: We wish to acknowledge the support of our donors who make Action on Invasives initiative possible, in particular UK Aid (FCDO-foreign and commonwealth office) and the DirectorateGeneral for International Cooperation (DGIS), The Netherlands. CABI is an international intergovernmental organization, and we gratefully acknowledge the core financial support from our member countries and lead agencies, including the United Kingdom (DFID), China (Chinese Ministry of Agriculture), Australia (Australian Centre for International Agricultural Research), Canada (Agriculture and Agri-Food Canada), The Netherlands (DGIS), and Switzerland (Swiss Agency for Development and Cooperation). See http:/ / www.cabi.org/about-cabi/who-we-work-with/key-donors/ (accessed on 14 May 2021) for full details.

Institutional Review Board Statement: Not applicable.

Data Availability Statement: The data presented in this study are available on request from the corresponding author. 
Acknowledgments: We extend our gratitude to Lorraine Strathie of the ARC-PHP, Cedara, South Africa, for guidance during the experiments and support in the biological control of parthenium. We are grateful to Angela Bownes of the ARC-PHP, Cedara, South Africa, for conducting no-choice tests on sunflower cultivars. We are grateful to the ARC-PHP, Cedara, for training researchers from Pakistan in South Africa and providing a starter colony of Listronotus setosipennis, facilitating this study. The authors would like to thank Daud Hussain Anjum, research associate for his contribution and dedication in the maintenance of the cultures in quarantine as well as data collection in Pakistan. We highly appreciate the facilitation of the Department of Plant Protection and Pakistan Agricultural Research Council, Pakistan in establishing the quarantine laboratory at CABI Pakistan Centre and granting permission to import L. setosipennis into Pakistan to undergo host range testing in quarantine. We extend our gratitude to the Pakistan National Insect Museum (NIM), National Agriculture Research Centre (NARC), Islamabad, for lodging specimens of Listronotus setosipennis under voucher specimen number $\mathrm{C} / 3666$.

Conflicts of Interest: The authors declare no conflict of interest.

\section{References}

1. Shabbir, A.; McConnachie, A.; Adkins, S.W. Spread. In Parthenium Weed: Biology, Ecology and Management; Adkins, S.W., Shabbir, A., Dhileepan, K., Eds.; CABI: Boston, MA, USA, 2019; Volume 7, pp. 40-56.

2. Mainali, K.P.; Warren, D.L.; Dhileepan, K.; Mcconnachie, A.; Strathie, L.; Hassan, G.; Karki, D.; Shrestha, B.B.; Parmesan, C. Projecting future expansion of invasive species: Comparing and improving methodologies for species distribution modeling. Glob. Chang. Biol. 2015, 21, 4464-4480. [CrossRef] [PubMed]

3. Adkins, S.W.; McClay, A.; Bajwa, A.A. Biology and ecology. In Parthenium Weed: Biology, Ecology and Management; Adkins, S.W., Shabbir, A., Dhileepan, K., Eds.; CABI: Boston, MA, USA, 2018; Volume 7, pp. 7-39.

4. Razaq, Z.A.; Vahidy, A.A.; Ali, S.I. Chromosome numbers in Compositae from Pakistan. Ann. Missouri Bot. Gard. 1994, 81, 800-808. [CrossRef]

5. Shabbir, A.; Dhileepan, K.; Adkins, S. Spread of parthenium weed and its biological control agent in the Punjab, Pakistan. Pak. J. Weed Sci. Res. 2012, 18, 581-588.

6. Adkins, S.W.; Navie, S.C. Parthenium weed: A potential major weed for agro-ecosystems in Pakistan. Weed Sci. Res. 2006, 12, 19-36.

7. Khaliq, A.; Aslam, F.; Matloob, A.; Hussain, S.; Tanveer, A.; Alsaadawi, I.; Geng, M. Residual phytotoxicity of parthenium: Impact on some winter crops, weeds and soil properties. Ecotoxicol. Environ. Saf. 2015, 122, 352-359. [CrossRef]

8. Wakjira, M.; Berecha, G.; Tulu, S. Allelopathic effects of an invasive alien weed Parthenium hysterophorus L. compost on lettuce germination and growth. Afr. J. Agric. Res. 2009, 4, 1325-1330.

9. Safdar, M.E.; Tanveer, A.; Khaliq, A.; Riaz, M.A. Yield losses in maize (Zea mays) infested with parthenium weed (Parthenium hysterophorus L.). Crop Prot. 2015, 70, 77-82. [CrossRef]

10. Safdar, M.E.; Tanveer, A.; Khaliq, A.; Maqbool, R. Critical competition period of parthenium weed (Parthenium hysterophorus L.) in maize. Crop Prot. 2016, 80, 101-107. [CrossRef]

11. Bajwa, A.A.; Ullah, A.; Farooq, M.; Chauhan, B.S.; Adkins, S. Competition dynamics of Parthenium hysterophorus in direct-seeded aerobic rice fields. Exp. Agric. 2019, 56, 196-203. [CrossRef]

12. Bajwa, A.A.; Ullah, A.; Farooq, M.; Chauhan, B.S.; Adkins, S. Effect of different densities of parthenium weed (Parthenium hysterophorus L.) on the performance of direct-seeded rice under aerobic conditions. Arch. Agron. Soil Sci. 2019, 65, 796-808. [CrossRef]

13. Bajwa, A.A.; Farooq, M.; Nawaz, A.; Yadav, L.; Chauhan, B.S.; Adkins, S. Impact of invasive plant species on the livelihoods of farming households: Evidence from Parthenium hysterophorus invasion in rural Punjab, Pakistan. Biol. Invasions 2019, 21, 3285-3304. [CrossRef]

14. Bajwa, A.A.; Asad, S.; Adkins, S.W. Interference and impact of parthenium weed on agriculture. In Parthenium Weed: Biology, Ecology and Management; Adkins, S.W., Shabbir, A., Dhileepan, K., Eds.; CABI: Boston, MA, USA, 2018; Volume 7, pp. 57-78.

15. Greathead, D.J. Benefits and risks of classical biological control. In Biological Control; Hokkanen, H.M.T., Lynch, J.M., Eds.; Cambridge University Press: Cambridge, UK, 2010; pp. 53-63.

16. Zimmermann, H.G.; Moran, V.C.; Hoffmann, J.H. The renowned cactus moth, Cactoblastis cactorum: Its natural history and threat to native Opuntia floras in Mexico and the United States of America. Divers. Distrib. 2000, 6, 259-269. [CrossRef]

17. Javaid, A.; Shabbir, A. First Report of Biological Control of Parthenium hysterophorus by Zygogramma bicolorata in Pakistan. Pak. J. Phytopathol. 2006, 18, 199-200.

18. Dhileepan, K.; Callander, J.; Shi, B.; Osunkoya, O.O. Biological control of parthenium (Parthenium hysterophorus): The Australian experience. Biocontrol Sci. Technol. 2018, 28, 970-988. [CrossRef]

19. Iqbal, I.M.; Ali, K.; Evans, H.C.; Rehman, A.; Seier, M.K.; Shabbir, A.; Weyl, P. The first record of Puccinia abrupta var. partheniicola, on Parthenium hysterophorus an invasive alien plant species in Pakistan. BioInvasions Rec. 2020, 9, 1-7. [CrossRef] 
20. Weyl, P.; Ali, K.; González-Moreno, P.; Ul Haq, E.; Khan, K.; Khan, S.A.; Hamza Khan, M.; Stewart, J.; Godwin, J.; Rehman, A.; et al. The biological control of Parthenium hysterophorus L. in Pakistan: Status quo and future prospects. Manag. Biol. Invasions 2021, 12. [CrossRef]

21. Wild, C.H.; McFadyen, R.E.; Tomley, A.J.; Willson, B.W. The biology and host specificity of the stem-boring weevil Listronotus setosipennis [Col.: Curculionidae] A potential biocontrol agent for Parthenium hysterophorus [Asteraceae]. Entomophaga 1992, 37, 591-598. [CrossRef]

22. Mersie, W.; Alemayehu, L.; Strathie, L.; McConnachie, A.; Terefe, S.; Negeri, M.; Zewdie, K. Host range evaluation of the leaf-feeding beetle, Zygogramma bicolorata and the stem-boring weevil, Listronotus setosipennis demonstrates their suitability for biological control of the invasive weed, Parthenium hysterophorus in Ethiopia. Biocontrol Sci. Technol. 2019, 29, 217-229. [CrossRef]

23. Winston, R.L.; Schwarzlander, M.; Hinz, H.L.; Day, M.D.; Cock, M.J.W.; Julien, M.H. Biological Control of Weeds: A World Catalogue of Agents and Their Target Weeds, 5th ed.; USDA Forest Service, Forest Health Technology Enterprise Team: Morgantown, WV, USA, 2014.

24. Wapshere, A.J. A strategy for evaluating the safety of organisms for biological weed control. Ann. Appl. Biol. 1974, 77, 201-211. [CrossRef]

25. Funk, V.A. Systematics, Evolution, and Biogeography of Compositae; International Association for Plant Taxonomy: Vienna, Austria, 2009.

26. Schaffner, U. Host range testing of insects for biological weed control: How can it be better interpreted? Bioscience 2001, 51, 951-959. [CrossRef]

27. Strathie, L.W.; McConnachie, A.J.; Retief, E. Initiation of biological control against Parthenium hysterophorus L. (Asteraceae) in South Africa. Afr. Entomol. 2011, 19, 378-392. [CrossRef]

28. Ali, K.; Rehman, A.; Khan, K.; Weyl, P. Comparative Efficacy of Common Broad Leaf Herbicides against an Invasive Weed: Parthenium hysterophorus L. Agric. Sci. 2020, 11, 617-626. [CrossRef]

29. Goodall, J.; Braack, M.; de Klerk, J.; Keen, C. Study on the early effects of several weed-control methods on Parthenium hysterophorus L. Afr. J. Range Forage Sci. 2010, 27, 95-99. [CrossRef]

30. Day, M.; Witt, A.; Winston, R. Weed biological control in low-income and middle-income countries. Curr. Opin. Insect Sci. 2020, 38, 92-98. [CrossRef] [PubMed]

31. Dhileepan, K.; Cruttwell, R. Parthenium hysterophorus L.-Parthenium. In Biological Control of Weeds in Australia; Julien, M., McFadyen, R.E., Cullen, J., Eds.; CSIRO Publishing: Melbourne, Australia, 2012; pp. 448-462. 